Teachers and

TEACHING

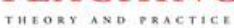

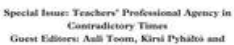

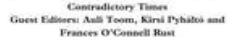

\section{Teachers and Teaching}

theory and practice

\title{
The role of beliefs in teacher agency
}

\section{Gert Biesta, Mark Priestley \& Sarah Robinson}

To cite this article: Gert Biesta, Mark Priestley \& Sarah Robinson (2015) The role of beliefs in teacher agency, Teachers and Teaching, 21:6, 624-640, DOI: 10.1080/13540602.2015.1044325

To link to this article: http://dx.doi.org/10.1080/13540602.2015.1044325

\section{( ๑) 2015 The Author(s). Published by Taylor \& Francis}

曲 Published online: 15 Jun 2015.

Submit your article to this journal

Џll Article views: 706

Q View related articles $\sqsubset$

View Crossmark data $\pi$ 


\title{
The role of beliefs in teacher agency
}

\author{
Gert Biesta $^{\mathrm{a}, \mathrm{b} *}$ (D), Mark Priestley ${ }^{\mathrm{c}}$ (D) and Sarah Robinson ${ }^{\mathrm{d}}$ \\ ${ }^{a}$ Department of Education, Brunel University London, UK; ${ }^{b}$ ArtEZ Institute of the Arts, \\ Arnhem, The Netherlands; ' School of Education, University of Stirling, Stirling, Scotland, \\ UK; ${ }^{d}$ Centre for Teaching Development and Digital Media, Aarhus University, \\ Aarhus N, Denmark
}

(Received 10 July 2014; accepted 13 October 2014)

\begin{abstract}
There is an ongoing tension within educational policy worldwide between countries that seek to reduce the opportunities for teachers to exert judgement and control over their own work, and those who seek to promote it. Some see teacher agency as a weakness within the operation of schools and seek to replace it with evidence-based and data-driven approaches, whereas others argue that because of the complexities of situated educational practices, teacher agency is an indispensable element of good and meaningful education. While the ideological debate about the shape and form of teacher professionalism is important, it is equally important to understand the dynamics of teacher agency and the factors that contribute to its promotion and enhancement. In this paper, we draw from a two-year study into teacher agency against the backdrop of large-scale educational reform - the implementation of Scotland's Curriculum for Excellence - in order to explore these questions. We focus on teachers' beliefs in order to get a sense of the individual and collective discourses that inform teachers' perceptions, judgements and decision-making and that motivate and drive teachers' action. While the research suggests that beliefs play an important role in teachers' work, an apparent mismatch between teachers' individual beliefs and values and wider institutional discourses and cultures, and a relative lack of a clear and robust professional vision of the purposes of education indicate that the promotion of teacher agency does not just rely on the beliefs that individual teachers bring to their practice, but also requires collective development and consideration.
\end{abstract}

Keywords: teacher agency; beliefs; professionalism; teaching; curriculum; educational change

\section{Introduction}

There is an emerging tendency in curriculum policy in the UK and elsewhere to acknowledge the importance of teachers' agency - that is, their active contribution to shaping their work and its conditions - for the overall quality of education (see, e.g. Goodson, 2003; Nieveen, 2011; Priestley, 2011). This is a significant shift given several decades of policies that worked to de-professionalise teachers by taking agency away from them and replacing it with prescriptive curricula and oppressive regimes of testing and inspection (see Biesta, 2010). The [re]turn to teacher agency not only gives explicit permission to teachers to exert high[er] degrees of

*Corresponding author. Email: gertbiesta@gmail.com 
professional agency within the contexts in which they work, but actually sees agency as an important dimension of teachers' professionalism. Yet the renewed emphasis on teacher agency raises a number of questions. These are partly about definition and theory, such as the question of what we mean by agency and more specifically teacher agency, and what it would mean for teachers to be active agents in and of their work. And they are partly empirical questions, particularly about the factors that promote or hinder teacher agency. In this paper, we focus on the latter set of questions, and more specifically on how teachers' beliefs play a role in their achievement of agency.

The paper is based on research conducted in the Teacher Agency and Curriculum Change project, which ran during 2011 and 2012. The project was carried out at the University of Stirling (Scotland), in partnership with a Scottish Local Authority, and was funded by the UK Economic and Social Research Council (ESRC). The research comprised a number of in-depth ethnographic case studies in three Scottish schools (primary and secondary). The immediate occasion for the research was the implementation of Scotland's new Curriculum for Excellence, a policy that aimed to change the structure, content and method of Scottish education. Curriculum for Excellence can be seen as an example of modern curricular reform in which teachers are explicitly positioned as agents of change, which made it a particularly suitable context for the study of teacher agency (see Priestley \& Biesta, 2013). The project focused on the ways in which and the extent to which experienced teachers achieve agency in their day-to-day working contexts against the background of the introduction of the new curriculum, and on the factors that promote or inhibit such agency.

Our paper is organised in the following way. We start with a discussion of the notion of agency and the way in which we have theorised and conceptualised it in our research, and locate the role of teachers' beliefs within this framework. We then provide a brief description of the design of the research upon which this paper is based. Against this background we present and discuss findings from the research, focusing on three areas of teachers' beliefs: beliefs about children and young people; beliefs about teaching; and beliefs about the purposes of education. In the discussion section, we explore what this reveals about the role of beliefs in teacher agency.

\section{Theorising agency}

Teacher agency, that is, agency that is theorised specifically in respect of the activities of teachers in schools, has been subject to little explicit research or theory development (Vongalis-Macrow, 2007). While there is some literature that locates the concept in relation to wider theoretical discussions of agency (e.g. Pignatelli, 1993; Priestley, Edwards, Priestley, \& Miller, 2012; Pyhältö, Pietarinen, \& Soini, 2012), existing change models tend to both underplay and misconstrue the role of teacher agency in educational change (Leander \& Osborne, 2008), albeit that a more interesting body of work is beginning to emerge (e.g. Eteläpelto, Vähäsantanen, Hökkä, \& Paloniemi, 2013; Priestley, Biesta, \& Robinson, in press).

Unlike teacher agency, agency per se has been extensively theorised, particularly in sociological literature in the context of ongoing discussions about the merits of holistic and individualistic explanations of social action (Hollis, 1994), a discussion known as the structure-agency debate. In recent years, attempts have been made to find a middle ground or indeed to reframe the terms of the debate altogether. These include Bourdieu's (1977) notion of 'habitus', Giddens's (1984) theory of 
'structuration', Archer's (1995) realist social theory or Elias's (2000) conception of 'figuration'. While such work has done a great deal in refining our understanding of the factors that pertain to social action, it is important to acknowledge that this discussion is predominantly located within a sociological problematic where, as said, the main ambition is the explanation of social action.

Our interest, however, is in the phenomenon of agency itself and in how agency is achieved in concrete settings and in and through particular ecological conditions and circumstances (see Biesta \& Tedder, 2006). This ecological understanding of agency is not sociological but has its roots in action-theoretical approaches, particularly those stemming from pragmatist philosophy (Dewey, Mead), where agency is concerned with the way in which actors 'critically shape their responses to problematic situations' (Biesta \& Tedder, 2006, p. 11). Here, rather than seeing agency residing in individuals, agency is understood as an emergent phenomenon of actor-situation transaction.

[T] his concept of agency highlights that actors always act by means of their environment rather than simply in their environment [so that] the achievement of agency will always result from the interplay of individual efforts, available resources and contextual and structural factors as they come together in particular and, in a sense, always unique situations. (Biesta \& Tedder, 2007, p. 137; emphasis added)

Agency, in other words, is not something that people can have - as a property, capacity or competence - but is something that people $d o$. More specifically, agency denotes a quality of the engagement of actors with temporal-relational contexts-for-action, not a quality of the actors themselves. In our conceptualising of agency we have further been guided by the work of Emirbayer and Mische (1998) who, building on pragmatism, have argued for a conception of agency that aims to overcome the one-sidedness of existing theories of agency which, in their view, tend to focus either on routine (acquired patterns of action), or on purpose (motivating 'forces'), or on judgement (the engagement with the situation in the here-and-now). They make a case for a conception of agency which encompasses the dynamic interplay between these three dimensions and which takes into consideration 'how this interplay varies within different structural contexts of action' (Emirbayer \& Mische 1998, p. 963).

They suggest that agency should be understood as a configuration of influences from the past, orientations towards the future and engagement with the present. They refer to these three dimensions as the iterational, the projective and the practicalevaluative dimension, respectively. In concrete actions all three dimensions play a role, but the degree to which they contribute in concrete achievements of agency varies. This is why Emirbayer and Mische speak of a 'chordal triad of agency within which all three dimensions resonate as separate but not always harmonious tones' (Emirbayer \& Mische 1998, p. 972; emphasis in original). Agency is then defined as:

the temporally constructed engagement by actors of different structural environments the temporal-relational contexts of action - which, through the interplay of habit, imagination, and judgement, both reproduces and transforms those structures in interactive response to the problems posed by changing historical situations. (Emirbayer \& Mische 1998, p. 970; emphasis in original)

The iterational dimension of agency has to do with 'the selective reactivation by actors of past patterns of thought and action, routinely incorporated in practical activity, thereby giving stability and order to social universes and helping to sustain identities, interactions, and institutions over time' (Emirbayer \& Mische 1998, 
p. 971; emphasis in original). The projective dimension encompasses 'the imaginative generation by actors of possible future trajectories of action, in which received structures of thought and action may be creatively reconfigured in relation to actors' hopes, fears, and desires for the future' (Emirbayer \& Mische 1998; emphasis in original). The practical-evaluative dimension entails 'the capacity of actors to make practical and normative judgements among alternative possible trajectories of action, in response to the emerging demands, dilemmas, and ambiguities of presently evolving situations' (Emirbayer \& Mische 1998; emphasis in original). Emirbayer and Mische's analysis emphasises the importance of context and structure in that agency is seen as the 'temporally constructed engagement with different structural environments' (Emirbayer \& Mische 1998, p. 970; emphasis added). The combination of context and time highlights that it is not only important to understand agency in terms of the individual's lifecourse. It is at the very same time important to understand transformations of contexts-for-action over time. According to Emirbayer and Mische, such contexts are primarily to be understood as social contexts in that agency is 'always a dialogical process by and through which actors immersed in temporal passage engage with others within collectively organized contexts of action' (Emirbayer \& Mische 1998, p. 974).

Combining our ecological conception of agency-as-achievement with ideas from Emirbayer and Mische has led to the following model (Figure 1), which has guided the design, data-collection and data-analysis and interpretation of our research.

This model highlights that the achievement of agency is always informed by past experience, including personal and professional biographies; that it is orientated towards the future, both with regard to more short-term and more long-term perspectives; and that it is enacted in the here-and-now, where such enactment is influenced by what we refer to as cultural, material and structural resources. For the focus of this paper, the model helps to generate more precise questions about the role of beliefs in the achievement of agency. These include the following questions: Where do teachers' beliefs come from (the iterational dimension)? How do beliefs

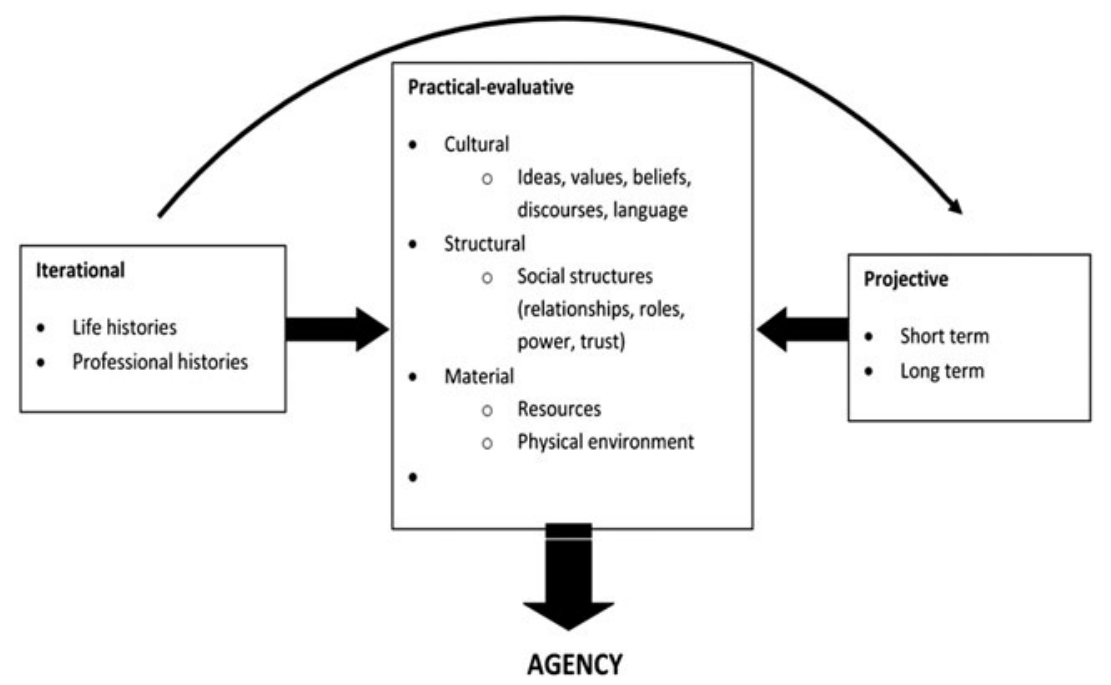

Figure 1. A model for understanding the achievement of agency. 
'motivate' action (the projective dimension)? How do beliefs influence what is actually done, that is, how do they function as resources for engagement in the concrete situations in and through which teachers act?

The term 'teacher beliefs' has been widely used in the educational literature to explain classroom decision-making (e.g. Meirink, Meijer, Verloop, \& Bergen, 2009; Nespor, 1987; Pajares, 1992; Wallace \& Priestley, 2011). Nespor (1987) views teacher beliefs as affective, narrative in nature and relying on correspondences with evaluations from the past, such as a particular student being 'immature' or 'bright'. Such a view highlights the iterational dimension of agency, that is, the fact that beliefs play a role in the way in which past experience impacts on the achievement of agency. Meirink et al. (2009) include intentions and expectations in their construct of teacher beliefs, thus highlighting the way in which beliefs play a role in the iterational dimension of the achievement of agency. The distinction between aspirations and beliefs is helpful to highlight the way in which beliefs can have an orientation towards the future and thus play a particular 'driving' or 'motivating' role in the achievement of agency. Nonetheless we view the distinction between aspirations and beliefs as analytical, that is, that aspirations are seen as one particular category of beliefs.

\section{Design}

This paper draws upon ethnographic research undertaken within a single education authority in Scotland, in one primary school and two secondary schools, focusing on two experienced classroom teachers in each setting. We also interviewed senior managers in each school. In this paper, we have primarily drawn upon the stories of the six classroom teachers to illustrate the themes relating to teacher beliefs that emerge from the data. The research covered a full year in the life of the school, with data-collection undertaken over three distinct phases following an iterative design, where each phase was partially determined by the findings of the previous phase. Data-collection involved observation; semi-structured individual and group interviews, including, at the start of the project, a personal and professional history interview; analysis of key policy texts; and teacher network mapping.

The analysis in this paper is drawn from interview data from all three phases of the project. For the purpose of this paper, these data were first analysed using a set of codes derived from the model depicted in the diagram below. This allowed us to sort the interview transcripts into themes relating to the agency model. Relevant excerpts from the interviews were then further analysed, using a process of open coding, to provide a more nuanced account of these teachers' beliefs and aspirations, and allowing us to interpret how their agency was shaped by these factors. The organisation of the discussion in terms of beliefs about children and young people, about teaching and about the purposes of education emerged from this analysis.

All participants have been designated by letter to protect anonymity, but allowing readers to see who has said what through the paper. Given that a great deal of what was said to us might be seen as especially sensitive, or place participants at risk, we have further anonymised the data by making only generic reference to the teachers' roles (for example, we have not made reference to teaching subjects, nor in the majority of instances whether the respondents are primary or secondary teachers). The research adheres to the guidelines for the ethical conduct of research of the British Educational Research Association. 


\section{Teachers' beliefs}

In this section of the paper, we describe and discuss beliefs articulated by teachers participating in the research. We do this under three headings: beliefs about children and young people; beliefs about teaching; and beliefs about educational purpose. In analysing the data, we were struck by the similarity of beliefs articulated across this small group of teachers, despite their location in different sectors of education. These teachers largely shared a professional discourse that seemed to frame many of their beliefs about students and their roles as teachers, as well as their views on the purposes of education in quite similar ways. As we show in more detail below, these discourses appear to be fairly restricted in scope, more geared to short-term goals, and predominantly articulated via the language of recent policy documentation. This raises important questions about the nature and scope of the discursive resources teachers have available to them and how this impacts on their achievement of agency or lack thereof.

We offer a strong caveat about this before embarking on our discussion, as some of the ensuing discussion may seem to portray the teachers in a negative light. This is not our intention, and we would emphasise at the outset that we were impressed throughout the project with the professionalism, competence and dedication of all of the teachers who participated in the research. Moreover, we emphasise - as depicted within our theoretical model - that agency is not simply a matter of individual capacity (and belief is merely a subset of this). As an ecological construct it is also subject to structural, cultural and material influences. Teacher professional discourses are to a large extent as they are because of the teachers' positioning within their professional environments, and their agency (or lack of) is heavily influenced by factors which are often beyond their immediate control.

\subsection{Beliefs relating to children and young people}

The data clearly convey the strong sense of teachers' professional responsibility towards their students. The teachers reported working long hours, including work taken home. The secondary teachers talk of using their free time in school to focus on students' needs and issues, a knock-on consequence being that planning and other curricular work had to be done out of school working hours. All the teachers believed that the relationships they developed with their students were critical to establishing what they would generally refer to as a framework for learning. The significance of what was often referred to as a safe and caring learning environment for everyone who came into their classrooms was articulated strongly. In general, these were teachers who wished to do their best for their students, and who frequently talked in terms of maximising student potential. We will come back to this construct in due course when we discuss the beliefs of the teachers relating to purposes of education, but note it at this point in relation to the positive professional orientation of the teachers towards students.

Nevertheless, these generally positive aspects were tempered by what might be seen as a deficit view of children. This view was exhibited, tacitly at least, through use of particular language by the majority of the teachers participating in our research, suggesting the presence of strong professional discourses about children that in turn seem to limit teacher agency in particular ways in respect of curriculum development. A strong discourse lay in the repeated use by teachers of terms like 
'able', 'bright' or 'poor' to describe their students. Examples of this sort of language can be found in the following excerpts.

The more able pupils still want classroom teaching from the front. They want to have things written down. They want to be taught in the old established way of teaching and that is what they want because they see that as their route to get to further education. The less able pupils prefer the less structure but they are in actual fact the ones who are less able to manage their own learning. (Teacher A)

You have got a really gifted able child and you have got a pupil who can barely read and write at a secondary level, they are still in primary two, three reading, writing ability. (Teacher B)

In my opinion that is the right thing especially for people who are not the brightest. They need life skills. They need skills to be able to help them in areas that they are maybe not so great at. (Teacher C)

These quotes are interesting on a number of levels. For example, they strongly suggest that many teachers continue to see education primarily in terms of its qualification function (Biesta, 2010), with a concomitant emphasis on getting through the syllabus. In the light of such perception of the teacher's job, our data suggest that some teachers see the inclusion of less able children in their classes as unhelpful. Such language suggests that many teachers continue to see ability as a unitary and fixed concept, despite the recent prevalence in educational discourse of notions of multiple intelligence and learning styles, for example.

Interestingly, these latter discourses were also strongly evident in our transcripts, suggesting that a contested and often confused terrain of competing discourses underpins teachers' practices. For instance, teachers talked a great deal about personalisation and choice, such as in the following example.

If you understand that you have individuals in your classroom and not a homogeneous group, then you can respond differently and have different strategies and different goals that are appropriate to whichever person is in front of you at that time. (Teacher A)

Another theme that seems to lie in some tension to the espoused notions of ability described above, relates to teachers' views about pupils becoming more responsible for their own learning - a trend termed 'responsibilisation' by Davies (2006). Such discourses underpin Curriculum for Excellence, and this language was used regularly by our respondents, including in ways that contradict other beliefs about children. Two teachers spoke about the shift from knowledge to skills in the new curriculum, suggesting that their role was to now develop:

... independent learners. Confident about being given a task and using the right skills in order to do it the best way they can. (Teacher C)

Another teacher explained it similarly.

You are teaching a lot of the skills that we want the children to have, the independence, working on their own, choosing what they are doing, deciding which way ... (Teacher D)

Still another teacher put it far more explicitly, giving some revealing insights into her views about the relative responsibility afforded to teachers and pupils.

Could you imagine a teacher turning round to the kids and saying, 'right I am just going to fail you all because I could not be bothered doing the marking'. But that is 
effectively what they are doing by saying, 'can I not just drop out'. So it is infuriating when you make the decision that 'right, I am going to need to do this' but the kids just seem to back off. It does get your blood boiling a little bit ... But then you think in that case, 'how much influence could I actually have' because what if they are deciding that and then they have not got a parent at their back saying, 'no, computer off, homework'. So I do not know. There is [sic] some kids I will never get through to. (Teacher B)

One teacher, who expressed strong support throughout her interviews for Curriculum for Excellence and the notion of students taking responsibility for their own learning, suggested that this idea was problematic because of the capabilities of the students themselves.

No, they do not actually understand what responsibility for their own learning is. And they are not capable of managing it. (Teacher A)

The above discourses are illustrative of tensions in teachers' beliefs about children and young people and their abilities and capabilities. They partly see their role as a directive and active one - to fix perceived deficits in students that have their roots in social backgrounds and general levels of ability. And yet, at a rhetorical level at least, and in potential tension with this directive role, these teachers buy into the discourses of the new curriculum, particularly with regard to responsibilisation. There is a sense here that there is a grey area in the issue of whose responsibility it is to ensure that learning takes place. Thus, students with 'poor' ability, or students who do not take 'responsibility' for their own learning provide a justification for the teacher to abdicate some professional responsibility, blaming students as 'mad, bad or stupid' (Watzlawick, Wickland \& Fisch, in Salomon, 1992, p. 45). Or conversely such traits provide a justification for the teacher to intervene to take charge and assume responsibility, and even on occasion to protect students from what might be considered to be faults in the education system.

An example of this latter tendency is found in one teacher's recourse to what has been termed 'protective mediation' (Osborn et al., 1997), a way of acting where teachers - agentically - seek to protect their students from aspects of policies and practices that they consider unhelpful or harmful. She mentioned that she sometimes gave tests without telling pupils that they were being tested. Upon being questioned about this practice, she stated that she believed that excessive testing placed harmful demands upon students; thus, while she felt obliged (by the system) to administer tests, she also sought to protect students from their worst excesses. Such action suggests a high degree of agency; this teacher clearly sees alternative courses of action, and her decisions in this matter are clearly driven by her beliefs about education and young people. The direction taken in such cases is likely to be highly dependent on how teachers see their own role in the process. This will be examined in the next section. We will return to teacher responsibility later in the paper, as this, along with the beliefs which underpin it, has profound implications for the agency achieved by teachers.

\subsection{Beliefs about the role of the teacher}

As with their beliefs about students, our participants displayed a largely homogeneous range of views about their roles as teachers. Most notable was a commonly acknowledged view that the role has changed - from that of a deliverer of 
knowledge to that of a facilitator of learning, and from a subject specialist to a teacher of children. We found this slightly surprising, given the previously discussed views of the teachers towards children's ability. It also seems to fly in the face of the prevalent and commonly expressed view that teachers - especially secondary teachers - are sceptical about both the pedagogical approaches advocated within Curriculum for Excellence and its apparent shift towards interdisciplinarity (for example, see Ford (2011) for an argument against a downgrading of subject knowledge). Indeed, only one participant strongly referred to the importance of subject knowledge, lamenting what she saw as the detrimental effects of vocationalism on the academic content of her subject. Again, as previously noted, such tensions are probably indicative of the confused educational discourses that surround the teachers' work.

All of the participants talked about their changed role as facilitators of learning and all seemed comfortable with this perceived shift. There was some evidence, as found in previous research, that the teachers were able 'to assimilate the messages of reform institutes without changing fundamental views of ... teaching' (Yerrick, Parke, \& Nugent, 1997 , p. 155), and to find ways 'to view potentially contrary messages in ways that accentuate their own beliefs' (p. 154). Thus, in some cases, this role was seen in an overtly student-centred and divergent manner:

I studied a bit of the background to [its] philosophy and realised how that is actually teaching them social skills as well. In a good way. And teaching them not just to assume things about people, or make assumptions about life. And really quite difficult critical thinking skills as well. It was difficult to teach that. You are not teaching it actually. You are a facilitator. (Teacher E)

In others, there seemed to be a more instrumental and directive approach, one suggesting convergence and following the demands of the syllabus:

The teacher's role is as a facilitator [laugh] to encourage and enable the learner. To have access to the stimulus you need to encourage them to make the right choices. Or to learn in a particular style. To jump through hoops and pass exams because, at the end of the day, that is how it is measured. (Teacher A)

A major focus of the new curriculum is to introduce more interdisciplinary work. In principle, this was applauded by many of the teachers, although the understanding of what that meant in practice caused concern, particularly in the secondary schools. This belies the sorts of views expressed by Ford (2011). One of the senior managers expressed his belief that interdisciplinary work was the way forward for the school. He went as far as to say that this kind of work made a 'good school', linking interdisciplinary work to student choice and to personalised learning.

This is what makes a good school; people should really have known that already about the importance of working across different faculties. The importance of giving personalisation and choice at the right time and giving guidance at the right time and so on. (Senior manager, secondary school)

The same manager believed that it was his responsibility to cultivate trust and confidence in his staff. He expected them to be willing to take risks and to try out new ideas. Such autonomy - the notion that teachers are to be agents of change within the new curriculum - elicited some interesting thoughts from some of the teachers. All of the participants expressed anxiety at the prospect of this. Two teachers in particular espoused views that are probably indicative of wider currents of thinking 
amongst Scottish teachers: deference to authority, a lack of willingness to take responsibility for issues seen to the remit of those further up the chain and nervousness about being 'required' to be autonomous in their work. One teacher, who in lots of ways was seen to achieve agency in her work, stated that:

You just do a good job. You try your best. You do not muck around. You do not do things you should not do or challenge superiors in a way unless it's obviously something genuine. (Teacher B)

Another expressed strong anxieties about curriculum development.

\begin{abstract}
Somebody goes on a course and they come back, we had girls on a course who came back and said 'this is just unbelievable what they are saying about it', 'you have got to take one statement in and unpack that whole thing and then put that into lots of other little statements and then work out how you are going to achieve delivering that or how you are going to do this'. And you just think, it is a job. I can't give more of my time, my time personally. I feel, I am in from 9 to 3 teaching the children and from 3 till, I know I am 3 till 6, and more, trying to prepare for the next day without having to then say 'when am I going to do all this?'. It is not feasibly possible. And every school, every council and every teacher are all trying to do this instead of somebody somewhere coming up with it. The E's and O's ${ }^{1}$ were meant to be there to declutter your programme but what you are wanting you to do now is to take that statement and then start building from it. (Teacher D)
\end{abstract}

Interestingly, despite this apparent reluctance to rock the boat, and/or to become more actively engaged in developing the curriculum in school, all of the teachers readily criticised a range of issues that they saw as impacting negatively on their ability to do their jobs. These included the impact of accountability, particularly what they saw as the overemphasis on attainment noted in the previous section (which is seen as being in tension with Curriculum for Excellence), a perceived tendency for teachers' voices to be ignored in favour of the views of people with little or no immediate connection with schools and workload issues. Many such complaints were framed by the fact that these teachers clearly took pride in their work. At first glance, it is puzzling how professionals can apparently abdicate responsibility for aspects of their work, and then complain that they are not being listened to. In the next section of the paper, we examine this issue in some more detail in the light of how these teachers view the purposes of education.

\title{
4.3. Beliefs about educational purpose
}

The teachers in this study demonstrated broadly similar beliefs about educational purpose. These tended to coalesce around a small number of key themes. Two key themes are socialisation, and the development of key skills or competencies. According to one teacher:

Well the main thing you would come straight away is for learning. But not just academic learning. You are building them as individuals to know how to relate to others, how to socialise, interact. To get them prepared for the wider world. (...) The socialisation part for me is really important. (...) Schools can provide kids with things that they might not get at home, some kids obviously. The chance to work with other people in a supportive environment. The chance to be part of a team. Not necessarily the actual explicit curriculum, what is going on behind the scenes. It is a place for kids to find themselves. (Teacher B)

Another teacher expressed similar views. 
With the Curriculum for Excellence ... they are focusing more on skills. And it is skills for learning, skills for work, skills for life that you are focusing on more. So when you are doing a topic, you are not always thinking about the knowledge that they are going to get from it. $\mathrm{Coz}$ is that knowledge ever going to be used? It is nice to learn things, facts but that cannot be transferred. That is not going to help them when they leave school [laughs]. Whereas the skills that help them learn those things or do a certain activity in a certain way is what will help them in the future. (Teacher C)

Several issues jump out from these transcripts, which broadly reflect views encountered in interviews with all of the teachers and senior managers. First, these views provide what we might term a rather instrumental engagement with the question of educational purpose, that is, seeing it more in terms of particular aims rather than with regard to the bigger question what education is for (see Biesta, 2010). While socialisation and skills development can be seen as long-term aspirations for the curriculum - in this regard they are not concrete 'learning outcomes' that can be achieved at the end of a single lesson - they are nonetheless concrete in their orientation. It might also be argued that such aims are somewhat convergent in nature, especially those relating to socialisation. These seem to be about the development of predetermined capacities and dispositions which are more about equipping students to function effectively in a society 'as is', rather than providing them with the skills to handle uncertainty, and to be agents of change in their own turn as they contribute to the development of a society that 'might be'.

Second, if one digs deeper into the discourses of skills development and socialisation expressed by these teachers, one is struck by what is missing. The teachers tended to articulate aims that are vague in nature: phrases such as 'reaching their potential' and 'finding themselves' are common in the data. There is talk of developing teamwork skills, and thinking skills, but no systematic evidence in the data of sense-making ${ }^{2}$ to further unpack what these mean, and little articulation of the fine detail. Often the aim of education is somewhat tautological: the aim of education is learning, but there is little clear picture of what is being learned, or why. Surprisingly, especially in the secondary schools, and as previously mentioned, there is little sense in our data of education as being about the acquisition of knowledge. Similarly, and perhaps equally surprising, there is also little about qualification or accreditation as a purpose of education. This is mentioned by some participants, but most often in negative terms (as a competing pressure), and rarely as an explicit purpose of education despite the high profile given to attainment data in Scottish schools. Also conspicuous by its absence is a discourse about educational values. At no point did any of our respondents talk, for example, about social justice or democratic values. Instead, the discourse seemed to rest with notions of personal responsibility and participation as core goals of citizenship, for which schools should prepare students (see Westheimer and Kahne (2004) for an extended discussion of these concepts in a North American context; and Biesta (2008) for an application of these ideas in the Scottish context).

Two further issues are worthy of mention in relation to educational purposes. The first concerns whether teacher aspirations are long- or short-term in nature. Addressing the first question, it is apparent that much of the professional dialogue about educational purpose is not in fact long-term. Where it is, and as noted above, there tends to be a fairly strong instrumental slant to it. Our data suggest that a large proportion of teacher aspirations in respect of their teaching are relatively short-term in nature, and that a good deal of day-to-day planning and activity is performed with 
this in mind. This concurs with earlier research (Brown \& McIntyre, 1993), which strongly suggested that teacher decision-making is driven by a perceived need to maintain a 'normal desirable state' in the classroom. The following excerpts provide a flavour of this, suggesting that much teacher agency is shaped by short-term aspirations to tick curricular boxes, deliver enjoyable lessons, keep students engaged and interested, and keep classes quiet and well behaved.

Very organised, loads of tasks, very Curriculum for Excellence hitting. Health and wellbeing, literacy and numeracy and [subject deleted], blah, blah, blah. All the things. And very much about working in a group. (Teacher A)

I think my priority is always engaging the kids and producing lessons that they like and enjoy and can relate to. And that is always my focus. And like I said in the background, floating in the edges, I'm aware of Curriculum for Excellence and that it does introduce changes. There is [sic] going to be 'having to think about it moments' in the future. But right now I don't feel like it's having that big an impact on a daily basis ... I want the kids to come in and enjoy my class and enjoy what we do. And that's always my priority. It's always the question I ask at the end of every lesson at the end of every day, 'am I doing a good job, are they enjoying it, are they not enjoying it?'. That's always my priority. (Teacher B)

I do like going and finding different things to do just to make it more interesting for me and for the children. And just coming with the times. (Teacher C)

For me it is the fun that they have. If they learn, you see them develop, regardless of how slow or fast it is. But they enjoy it. But also that I am enjoying it. The days that I know I have not enjoyed, I know that I am sometimes a bit more narky and maybe they are not enjoying it so much. When they do something, when they are smiling, particularly primary ones. (Teacher D)

This focus on process and the comparative lack of discourses around purpose and values strongly suggest a disconnection between purpose and method, and an impoverishment in teacher discourses which potentially reduces their agency, as well as the quality of education that emerges as a result of teacher engagement with Curriculum for Excellence. This latter danger is neatly encapsulated by this anguished extract from one interview.

And then you also wonder about the pupil experience. We had a visit from the inspector last week and he was following one of my sixth year pupils. And the [unclear words] this was the only class we did any work in. In another class they were making a poster. This is someone in sixth year, doing advanced higher something and they were making a poster. Now I am not saying making a poster is not a useful thing to do but it seems like the pupils are very, very fed up with making posters. It is like everyone has got the idea that Curriculum for Excellence is about making a poster about what you have learned. (Teacher E)

We will return to the issue of purpose in the final section of the paper, but it is first worth briefly dwelling upon a second issue. This relates to the language used by teachers in framing the projective. It is evident from our dialogues with teachers, and the above analysis, that a great proportion of the professional discourses, which frame their practices and contribute to their professional agency, have their origins in the language of policy. This is evident in the terminology used by the teachers, even where (as for example in the case described above of students taking responsibility for their learning) there were clearly large differences in how different teachers interpreted the terms used. This highlights a number of issues. First, these teachers seem to lack a systematic set of professional discourses over and above those 
provided by the language of policy. This potentially reduces their agency in developing the curriculum through limiting their potential to envisage different futures, and through denying them the language with which to engage critically with policy. Furthermore, in apparent lack of opportunities for systematic sense-making of the core concepts of Curriculum for Excellence, teachers' understandings of the concepts often remain superficial and vague. A number of teachers expressed overt doubts on this matter.

The actual Curriculum for Excellence philosophy, if that is the right use of the word, where it is all about the children, it is all about preparing them for all of these things but then they come up with something that is very airy fairy. (Teacher D)

Well it is the theories sound great and then what we are getting on bits of paper just seems like, 'oh we have to change this and do this'. And I do not know, it is overly complicated but then there is a mixture between outlines and then not enough detail. (...) Most people I have spoken to feel the same as I do, that they are fumbling about trying things. (Teacher E)

\section{Discussion and conclusions}

The above analysis raises some uncomfortable issues about the ways in which teachers engage with new curricular policy, and about their agency. Teacher agency is highly dependent upon the personal qualities that teachers bring to their work. Such capacity, which forms the major part of the iterational dimension of their agency, includes professional knowledge and skills, and in many senses, there is little doubt that the experienced teachers in our project are highly advanced in these respects. However, the iterational dimension also includes the beliefs and values that teachers bring to their work. Our data suggest that there are problematic issues in relation to these, and in relation to the cultures of schooling within which these teachers work. Part of the problem seems to lie in the often confused discourses encountered in schools, and in teachers' often superficial understandings of such discourses.

Many of the discourses of modern schooling appear to be a mishmash of competing and vague ideas - personalisation, choice, learning, subjects, etc. - and, in the absence of opportunities for systematic sense-making in schools, teachers are regularly left confused about their role. Arguably, much of the blame for this situation lies in externally imposed systems which alter the dynamics of schooling, leading to incremental change without the development of a clear philosophy of education to underpin the changes in question, and a professional collegiality that enables its development. It is notable that even in the school where we have previously reported a clear sense of purpose and purposeful relational structures to enabling collegial working (Priestley, Biesta, \& Robinson, 2012), we found little evidence of long-term thinking about the purposes of education. This perhaps says more about the cultures of schooling than the structures, reinforcing Fullan's (1993) dictum that change requires reculturing as well as restructuring.

This leads us onto questions of purpose and value - part of the projective dimension of agency. Our data suggest strongly that many teachers struggle to locate their work within deep consideration of the purposes of education. Teachers are driven by goals in their work, but such goals often seem to be short-term in nature, focusing on process rather than longer-term significance and impact. Where long-term effects are considered, they tend to be fairly narrowly conceived. Such a framing of purpose 
has, we believe, implications for the ways in which teachers achieve agency. The comparative lack of a clear vision about what education is for seems to seriously limit the possibilities for action to develop a good education. Purposes that are narrowly framed inevitably narrow consideration of what is possible, and frame subsequent action accordingly.

Salomon (1992) offers insights into this in terms of the professional responsibility of teachers, drawing a distinction between efficiency and effectiveness. Our data suggest that the teachers in our project were highly efficient in getting the job done, despite inevitable difficulties encountered in terms of social, cultural and material constraints on their work. These teachers had a large repertoire of technical responses to enable their lessons to run smoothly. They were effective in achieving certain short-term goals, for example introducing new forms of pedagogy that were deemed suitable for Curriculum for Excellence. One might also argue that there was a long-term effectiveness in socialising young people, particularly in terms of the schools running smoothly in the long-term. However, the data suggest a fairly narrow engagement with consideration of the 'effects' of education - 'desirable residues to be manifested later on' (p. 44).

Salomon argues that such approaches represent a derogation of teacher responsibility. He posits three types of teacher responsibility:

- A proper carrying out of role as teacher (necessary whether a teacher is transmitting content or orchestrating activity).

- Responsibility for learning processes and outcomes.

- Serious consideration of method and content in the light of normative and moral criteria - i.e. consideration of long-term educational purposes and values. This responsibility is about 'giving serious consideration to the desirable and less desirable long-term effects of the constantly improvised learning environment' (p. 46).

It is clear from our data that the first responsibility was taken seriously by the teachers in our project. The second is more of a grey area, given the discourses about shifting responsibility to students. Nevertheless, it is clear from our data that the teachers tended to take this responsibility very seriously as well. The third area of responsibility seems to be more problematic. The comparative absence of longterm discourses about the purposes of education appears to be a major deficit in the schools where our research was undertaken. Moreover, this is an issue of teacher agency. We would argue that such narrowness of vision and purpose limits and delineates teacher agency in particular ways, narrowly defining what is possible within the terrain opened up by Curriculum for Excellence.

The data presented in this paper, which obviously only refer to one particular though nonetheless interesting case, do indicate that teachers' beliefs matter for the extent to which and the degree in which teachers are able to achieve agency within the particular educational ecologies in which they work. What our particular approach to the issue of teacher agency helps to make visible is what role teachers' beliefs play, as we have been able to highlight in more detail beliefs from past experience - which impact on the iterational dimension of agency; beliefs orientated towards the future - which impact on the projective dimension; and beliefs that play a role in the here-and-now - which concern the practical-evaluative dimension of agency. Perhaps the most important finding in the particular case we have presented 
here, is the absence of a robust professional discourse about teaching and education more generally. We assume that the absence of such a discourse ties teachers to the particular beliefs that circulate in their practice and prevents them from locating such beliefs within such wider discourses. As a result the existing beliefs cannot be experienced as choices but appear as inevitable. Access to wider discourses about teaching and education would provide teachers with a perspective on the beliefs they and their colleagues hold, and would provide a horizon against which such beliefs can be evaluated. This is one important reason why we think that access to robust professional discourses about teaching does matter for teacher agency, and thus should be an important dimension of teacher education and further professional development (see also Biesta, 2015).

In our research, we have instead seen the prevalence of beliefs that are strongly orientated towards the here-and-now and that are also strongly influenced by current and recent policy rather than by more encompassing orientations about the wider purpose and meaning of schooling. The relative absence of a robust professional discourse that teachers can bring to the situations in which they work, and a relatively weak set of orientations towards the future, thus seems to limit the possibilities teachers have to utilise their beliefs in achieving agency within contexts that are to a significant degree - albeit not entirely - constructed by systems of accountability, which seem to prioritise and value certain modes of action over others. That such systems do not entirely determine the ecological space in which agency is achieved is shown by the fact that teachers are, at least at the discursive level, challenged to be more agentic. Nonetheless in our particular case this appears to be not enough to help teachers engaging in more agentic and proactive ways with the situations they are in.

Why a robust professional discourse about teaching and the wider purposes of education is absent in the cases we have discussed in this paper is an important question for further research. One question it raises has to do with teacher education and the extent to which contemporary teacher education can be a place where student teachers are exposed to and have the opportunity to engage with a range of educational discourses and discursive repertoires. A second question has to do with the way in which ongoing professional development for teachers is structured and organised. As a first speculation we wish to suggest that much teacher education may have become geared towards the instrumental side of the spectrum - that is, getting the job done - and has been steered away from a more intellectual engagement with teaching, school and society. With regard to the latter it may well be that policy exerts the greatest influence on teacher development, that is, that most opportunities for such development are geared towards getting up to speed with latest policy initiatives. Where these speculations are to the point, and whether they describe the situation of teacher education and teacher development more generally or whether there are important local, regional and national differences, is an important question for further research.

\section{Disclosure statement}

No potential conflict of interest was reported by the authors. 


\section{Notes}

1. 'E's and O's' is the common acronym used to refer to documentation produced by Education Scotland, which provides a very detailed 'translation' of the broad curriculum framework of Curriculum for Excellence. While this documentation has no legal status with regard to the implementation of Curriculum for Excellence, it nonetheless plays an interesting and to some degree influential role in the translation of the framework into practice, and thus affects teacher agency. For the documentation see: http://www.educationscotland.gov. $\mathrm{uk} /$ thecurriculum/howisthecurriculumorganised/experiencesandoutcomes/index.asp.

2. See Priestley et al. (2012) for further discussion of the mechanisms (or lack of) for sense-making to occur in schools.

\section{ORCID}

Gert Biesta (D) http://orcid.org/0000-0001-8530-7105

Mark Priestley (D) http://orcid.org/0000-0001-8276-7771

\section{References}

Archer, M. (1995). Realist social theory: The morphogenetic approach. Cambridge: Cambridge University Press.

Biesta, G. J. J. (2008). What kind of citizen? What kind of democracy? Citizenship education and the Scottish Curriculum for Excellence. Scottish Educational Review, 40, 38-52.

Biesta, G. J. J. (2010). Good education in an age of measurement: Ethics, politics, democracy. Boulder, CO: Paradigm.

Biesta, G. J. J. (2015). How does a competent teacher become a good teacher? On judgement, wisdom and virtuosity in teaching and teacher education. In R. Heilbronn \& L. Foreman-Peck (Eds.), Philosophical perspectives on the future of teacher education (pp. 3-22). Oxford: Wiley Blackwell.

Biesta, G. J. J., \& Tedder, M. (2006). How is agency possible? Towards an ecological understanding of agency-as-achievement (Working Paper 5). Exeter: The Learning Lives Project.

Biesta, G. J. J., \& Tedder, M. (2007). Agency and learning in the lifecourse: Towards an ecological perspective. Studies in the Education of Adults, 39, 132-149.

Bourdieu, P. (1977). Outline of a theory of practice. Cambridge: Cambridge University Press.

Brown, S., \& McIntyre, D. (1993). Making sense of teaching: Developing teachers and teaching. Buckingham: Open University Press.

Davies, B. (2006). Subjectification: The relevance of Butler's analysis for education. British Journal of Sociology of Education, 27, 425-438.

Elias, N. (2000). The civilizing process. Sociogenetic and psychogenetic investigations (Rev. ed.). Oxford: Blackwell.

Emirbayer, M., \& Mische, A. (1998). What is agency? American Journal of Sociology, 103, 962-1023.

Eteläpelto, A., Vähäsantanen, K., Hökkä, P., \& Paloniemi, S. (2013). What is agency? Conceptualizing professional agency at work. Educational Research Review, 10, 45-65.

Ford, C. (2011, December 19). The trouble and truth about Curriculum for Excellence. Times Educational Supplement Scotland, 35-36.

Fullan, M. (1993). Change forces: Probing the depths of educational reform. London: The Falmer Press.

Giddens, A. (1984). The constitution of society: Outline of the theory of structuration. Cambridge: Polity Press.

Goodson, I. F. (2003). Professional knowledge, professional lives. Maidenhead: Open University Press.

Hollis, M. (1994). The philosophy of social science: An introduction. Cambridge: Cambridge University Press. 
Leander, K. M., \& Osborne, M. D. (2008). Complex positioning: Teachers as agents of curricular and pedagogical reform. Journal of Curriculum Studies, 40, 23-46.

Meirink, J. A., Meijer, P., Verloop, N., \& Bergen, T. C. M. (2009). Understanding teacher learning in secondary education: The relations of teacher activities to changed beliefs about teaching and learning. Teaching and Teacher Education, 25, 89-100.

Nespor, J. (1987). The role of beliefs in the practice of teaching. Journal of Curriculum Studies, 19, 317-328.

Nieveen, N. (2011, September 14). Teachers' professional development in curriculum design in the Netherlands. Paper presented at the European Conference for Educational Research, Berlin.

Osborn, M., Croll, P., Broadfoot, P., Pollard, A., McNess, E., \& Triggs, P. (1997). Policy into practice and practice into policy: Creative mediation in the primary classroom. In G. Helsby \& G. McCulloch (Eds.), Teachers and the national curriculum (pp. 52-65). London: Cassell.

Pajares, M. F. (1992). Teachers' beliefs and educational research: Cleaning up a messy construct. Review of Educational Research, 62, 307-332.

Pignatelli, F. (1993). What can I do? Foucault on freedom and the question of teacher agency. Educational Theory, 43, 411-432.

Priestley, M. (2011). Whatever happened to curriculum theory? Critical realism and curriculum change. Pedagogy, Culture and Society, 19, 221-237.

Priestley, M., \& Biesta, G. J. J. (Eds.). (2013). Reinventing the curriculum: New trends in curriculum policy and practice. London: Bloomsbury Academic.

Priestley, M., Biesta, G. J. J., \& Robinson, S. (2012, April 13-17). Understanding teacher agency: The importance of relationships. A paper presented at the Annual Meeting of the American Educational Research Association, Vancouver, Canada.

Priestley, M., Biesta, G. J. J., \& Robinson, S. (in press). Teacher agency: An ecological approach. London: Bloomsbury.

Priestley, M., Edwards, R., Priestley, A., \& Miller, K. (2012). Teacher agency in curriculum making: Agents of change and spaces for manoeuvre. Curriculum Inquiry, 42, 191-214.

Pyhältö, K., Pietarinen, J., \& Soini, T. (2012). Do comprehensive school teachers perceive themselves as active professional agents in school reforms? Journal of Educational Change, 13, 95-116.

Salomon, G. (1992). The changing role of the teacher: From information transmitter to orchestrator of teaching. In F. K. Oser, A. Dick, \& J.-L. Patry (Eds.), Effective and responsible teaching: The new synthesis (pp. 37-49). San Francisco, CA: Jossey-Bass.

Vongalis-Macrow, A. (2007). I, Teacher: Re-territorialization of teachers' multi-faceted agency in globalized education. British Journal of Sociology of Education, 28, 425-439.

Wallace, C., \& Priestley, M. (2011). Teacher beliefs and the mediation of curriculum innovation in Scotland: A socio-cultural perspective on professional development and change. Journal of Curriculum Studies, 43, 357-381.

Westheimer, J., \& Kahne, J. (2004). Educating the "good" citizen: Political choices and pedagogical goals. Political Science and Politics, 37, 241-247.

Yerrick, R., Parke, H., \& Nugent, J. (1997). Struggling to promote deeply rooted change: The "filtering effect" of teachers' beliefs on understanding transformational views of teaching science. Science Education, 81, 137-159. 